\title{
Retention and Protention Methodology: Edmund Husserl's Phenomenology as a Multidimensional Design Approach
}

Nicolas Turchi

\section{Abstract}

Despite humans' common tendency to oversimplify the time dimension into a mere concatenation of events following a cause-effect chain deeply rooted in Newtonian's universal time, it is acknowledged that time and space represent an ever-changing continuum which is highly affected (if not determined) by the observer. E. Husserl, in his Phenomenology, provides a counterpart to Newton's unidirectional timeline in which past, present and future are no more fixed terms on which events are stationing. Instead, they are extremely complicated artefacts of the human mind that deploy memory as the main time-building device to project existence. Given this scenario, present (the ever-now) is precisely the moment when all the past experiences have built up through retention and immediately become future projection by a 'protention' mechanism. Arguably, this condition finds its extreme realization in the figure of the designer. This should be revitalized from its constraining association to space in favour of a more comprehensive role. The Architect, owing to computational tools and an ontological re-questioning of the discipline, is ultimately becoming the one who can draw connections through several dimensions and branches of knowledge. This paper ends with an academic investigation into a space/ time-oriented design approach that deploys human memory-construction processes and innovative time-based computational operations, providing a platform for further academic research on this line.

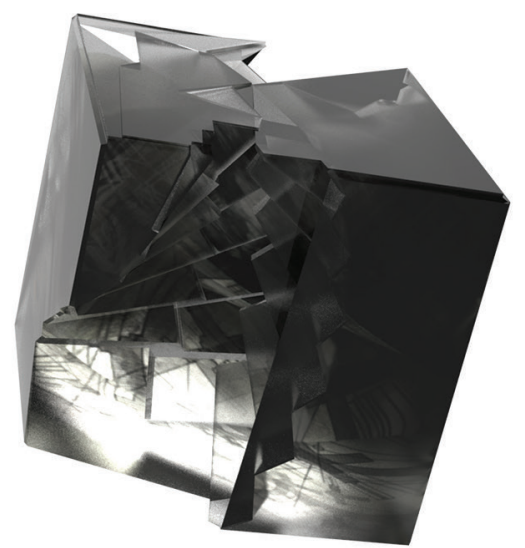




\section{Time account in Newton}

In his most famous work, Philosophiae Naturalis Principia Mathematica, published in 1687, Sir Isaac Newton outlined the primary laws that defined modern physics until Albert Einstein's special and general theories of relativity. In his studies on the qualities of objects in motion, he could not avoid encountering the problem of time. Newton's tendency to separate time from its relation to sensible objects of phenomena led him to establish the distinction between "absolute and relative, true and apparent, mathematical and common" time. [Newton 1934, p. 77]. Working by dichotomies, Newton attempted to establish what constitutes time. While absolute, true and mathematical time is not affected by any external factor and can be associated with the idea of 'duration' (still a very different concept of duration from that of Bergson's), the 'relative', apparent and common time is understood as a mere measure of the duration of motion. This second category of time, according to Newton, is a deceptive one. Newton strongly believed in an 'absolute time' (which we will refer to as 'Newtonian time') that goes uniformly without regard to any perceiver or physical event of any kind. Therefore, (absolute) time progresses at a consistent pace throughout the universe and can only be truly understood mathematically. "Place is that part of Space, either absolute or relative, that a 'Body' takes up. Absolute Motion is the translation of a body from one absolute place into another. Relative Motion is the translation of a body from one relative place into another" [Rynasiewicz 20 I4]. Newton asserted that all things are "placed in time and space' in a certain order; if they were to be moved out of their places, they would be moved 'out of themselves'. He describes everything placed in time as in order of succession and placed in space as in order of situation. Transformation has to be understood through motion which would be relative; therefore, it would fall into the deceptive category of time that Newton rejects.
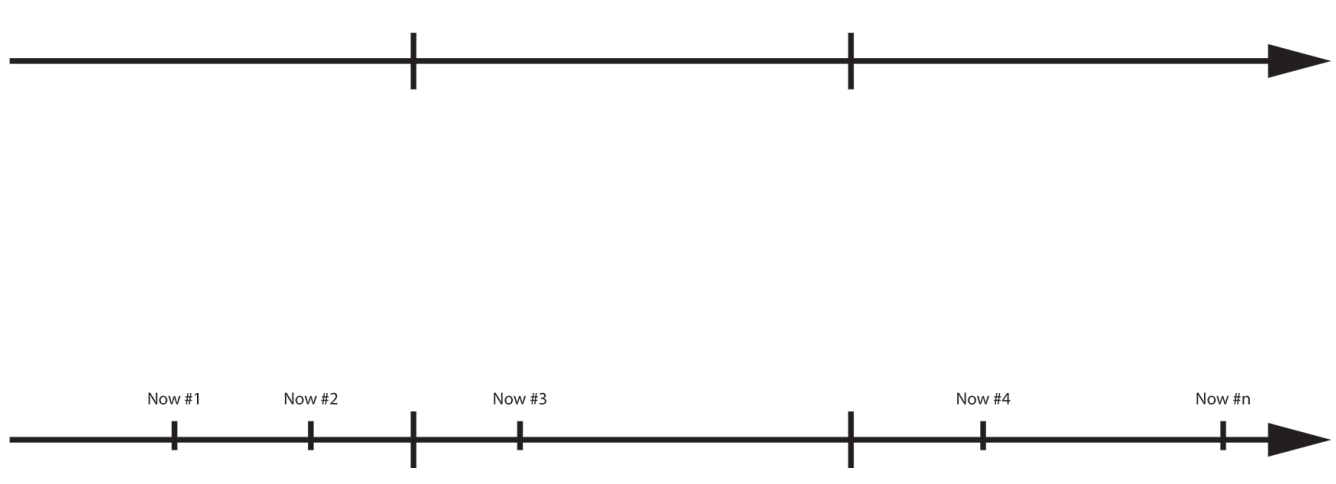

Newton's paradigm can be simplified into what is best known as a traditional timeline (fig. I). The chart synthesizes human beings' general experience of time in everyday life. Time flow is unidirectional and fixed; past, present and future are distinguished and cannot mix up, be reversed etc. This time conception is deeply rooted in our common grammar, the way information is processed in our brain and subsequently how a thought is formulated etc. Despite being central to humans' lives and the general understanding of time matter, Newtonian 'universal time' represents an extremely outdated view of reality and how time actually works. 


\section{Time account in Husserl}

A few centuries later, Albert Einstein's theories of relativity proved that space and time are not to be understood as separated entities but rather as a mathematically defined continuum. Furthermore, the idea of a model of the universe that is subject to relativity granted the observer an unprecedented key role in physics. Many authors, from disparate disciplines, were fascinated by the potential of this ontological revolution and, both in art and philosophy, speculations on these subjects flourished since the beginning of the XX Century. Among the many who contributed in this regard, Edmund Husserl focused on the relationship between the persistence of time and its perception in his work The Phenomenology of Internal Time-Consciousness. In this treatise, Husserl draws a link between the 'Immanent Object' itself and the 'Temporal Object', granting to the human being the role of the observer. A peculiar aspect of his temporal structure that deserves particular attention is the spatialization of the relationship between past, present and future. Husserl begins by considering the extremities of the nucleus of the discussion both in a figurative and a quite literal way. If there is a relationship of dependency between two instances $A$ and $B$, it implies a third one which can be considered the conjunction of both or the underlying status that is continuous at all stages. He further described time as a coexistence of a series of states of consciousness which partially rely on the flow of experiences (Erlebnisstrom). Focusing his attention to the nucleus that links the events, the German philosopher identified the 'now' as the orienting point, the one that generates the recognition of events either as 'no longer' or 'not yet' in analogy to McTaggart's second time series model (fig. 2).

Fig. 2. Husserl's Temporal Consciousness timelin The horizontal axis represents the series of now impressions. Below is the sinking in the retentional phenomenon ' $D$ ' is the 'now' moment took into the analysis. "E-E" represents the condensation of protention at the specific 'D' moment.

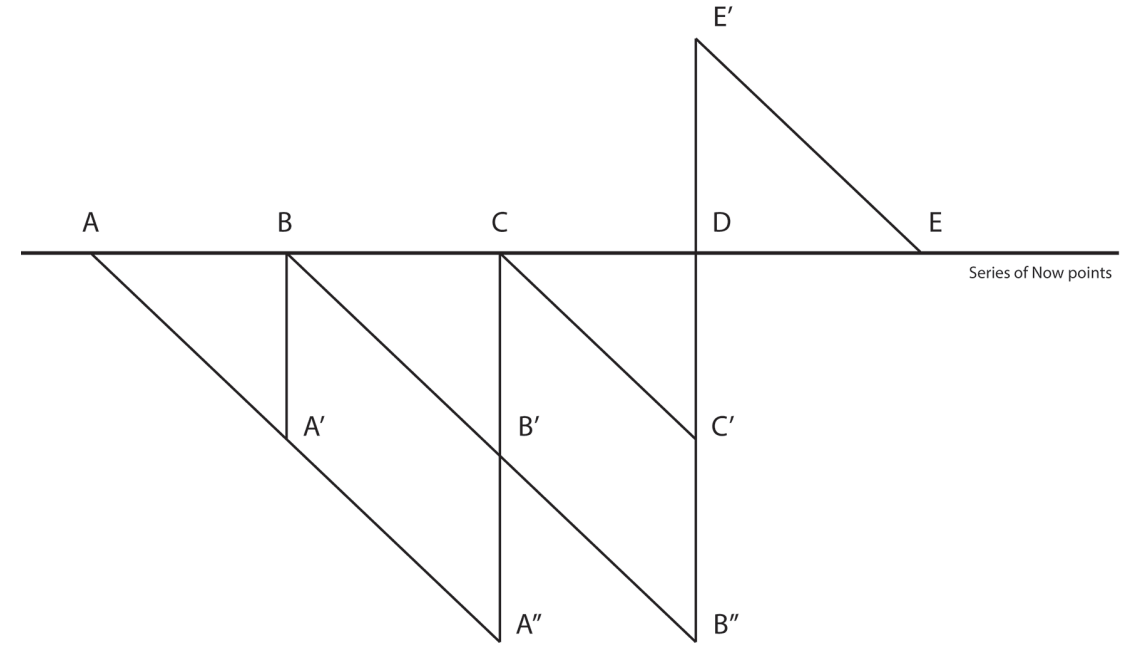

Conversely to Newton, Husserl did not describe time as a collection of fixed points on a timeline universally readable as containers of events. Instead, the now is composed of a synthesis of 're-tention' and 'pro-tention' moments and the network of relations between them. Retention is the act that makes us conscious of the immediate past temporal phases in the now we are living: "Of the interval that has expired we say that we are conscious of it in retentions, specifically, that we are conscious of those parts or phases of the duration, not sharply to be differentiated, which lie closest to the actual now-point with diminishing clarity, while those parts lying further back in the past are wholly unclear; we are conscious of them only as empty (leer)" [Husserl 1973, p. 46]. Protention is the anticipatory act that enables us to draw a prediction influenced by the inner research of continuity within the retention apparatus: "The same thing is true with regards to the running-off of the entire duration. Depending on its distance from the actual now, that part of the duration which lies closest still has perhaps a little clarity; the whole disappears in obscurity, in a void retentional consciousness, and finally disappears completely (if one may say so) as soon as retention ceases." [Husserl, 1973, p. 46]. 


\section{Husserl's phenomenology: the central role of the designer}

By its inherent nature, the human being constantly draws connections between the $\mathrm{A}$ and $\mathrm{B}$ parts composing the present (now). By placing the event in relation to preceding and succeeding events, we never perceive the now in isolation from past and future [Kelly 2020]. Therefore, we tend to experience time as a collapse of retentions and protentions. Even though past, present and future do not possess any particular quality per se, Husserl recognized that the entire structure of this phenomenon has a strong spatial character, "a kind of temporal perspective (within the originally temporal appearance) analogous to spatial perspective. As the temporal object moves into the past, it is drawn together on itself and thereby also becomes obscure" [Husserl 1973, p. 47].

Husserl provided an example to explain the interplay of these stages: a melody (other authors including Henri Bergson deployed the same analogy before). A melody can be simultaneously perceived in its totality as well as appreciated in its discrete moments, parts etc. Solely considering these components, obtained by timing the whole, would result in a series of 'now' moments that resemble those of the Newtonian 'universal time' (disconnected, mathematical and universal). However, in order for the whole melody to make sense out of a series of discrete junctures, it must be assumed that these imply a broader set of bilateral connections. These connections are constructed via retention and protention mechanisms. Only by appreciating the temporal object as a whole (e.g. a melody) and simultaneously by its constituent parts, eventually, it is possible to describe how consciousness experiences a temporal entity.

\section{Memory: retention and protention as designer major tools}

Adding to the previous illustration of a melody as a model of temporal entity and recalling the famous quote "architecture is frozen music" by Goethe, this research aims to underline the extremely close relationship between the essence of time-consciousness through the branching out of retention and protention networks at every now moment and the role of the designer.

On a very basic level, it can be argued that the act of designing a project (from the Latin projectus, proicere, meaning the act of throwing forth, stretching out) holds in itself a substantial series of information that works at several levels (professional, regulatory, educational etc. as well as relative to the specific instance: site condition and history, budget etc.). This information is obtained from a more or less recent past and flows into the now moment through retention (for obvious reasons it has been extremely simplified in grounded examples in this document). It is also true, as the etymology suggests, that the act of projecting is inherited from Husserl's Phenomenology, specifically inferring from the reflection of the 'running-off' phenomenon (fig. 3), highlighting the full potential of the protention process. Architecture is the discipline in which an extensive spectrum of specialities converge in a series of 'nows' entailing the full protentional potential of this convergence, eventually leading to a collective result (it being the realization of a building, a masterplan, a town planning scheme etc.). However, taking the discourse to a deeper level, the retention-protention structure systematically adapts and re-arranges itself in a series of ever-changing 'nows' that constitute the different phases of the project. As in the case of a melody, we should not mistakenly consider each phase as exclusively affected by a single aspect of this duality. The relationship will remain mutual: an early stage approach to the project that very often coincides with the gathering of documentation is already deeply affected by projections into the (more or less) near future, and a built work preserves a pool of possible projections that spawn from retention (e.g. publications, MEP maintenance etc.).

Recent studies [Schacter et al. 2013] have demonstrated that evoking memories involves the same neural structures that are triggered when making future projections, adding a creative component to the entire process. This suggests that our memories might be much farther from reality than what we imagine. Furthermore, the virtual gap between retention 
Fig. 3. 'Running-Off' phenomenon in Husserl's timeline. The series of 'now' moments (A,B,C,D,E...) is subtended by both its retentional and protentiona protentional (In red) projoction of every now moment is ind $B(p), C(p), D(p) \ldots$
Fig. 4. A design speculation applying the retention-protention structure. Animated Boolean through platonic shape through platonic shape is operating at multiple levels. actual geometry boolean operations, texture mapping with alpha channel subtraction line drawing defining the same object projected and distorted on top of the geometry while this is animated in time. and protention is currently undergoing a progressive acceleration owing to immersive technologies and media that are altering the experience of the 'now'. Among other professional figures, architects are constantly exposed and extensively rely on computational tools both during the creative process as well as when using them as mediums of representation. Given this framework, it is critical to the discipline to expand beyond the misleading self-definition of a spatial-oriented field. Time, and particularly consciousness of time, becomes critical in defining design and academic agenda along with the advancing of new media and computational tools.

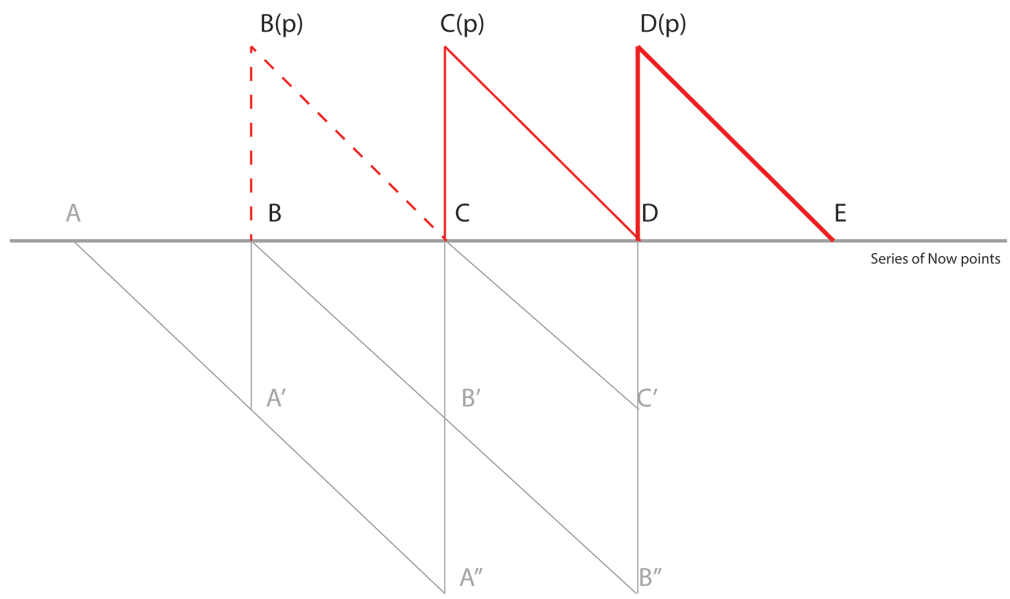

\section{Furthering the research: an academic case study}

The following work is extracted from a recent thesis from the Master in Architecture II at the Harvard Graduate School of Design, Cambridge, US. As mentioned previously, the thesis investigates how the artificial consciousness of time, based on Husserl's assumptions, can be incorporated within the design process, inserting the fourth dimension in a workflow that deploys new digital techniques including simulation and animation engines.

The project site is the Bishopsgate Goodsyard in the heart of Shoreditch in London. The site is consumed by infrastructure and urban decay. The proposed program for the main building is the new Shoreditch High Street over ground station, Transport facility for the London headquarters and the Physics Dept. for the New University of London.

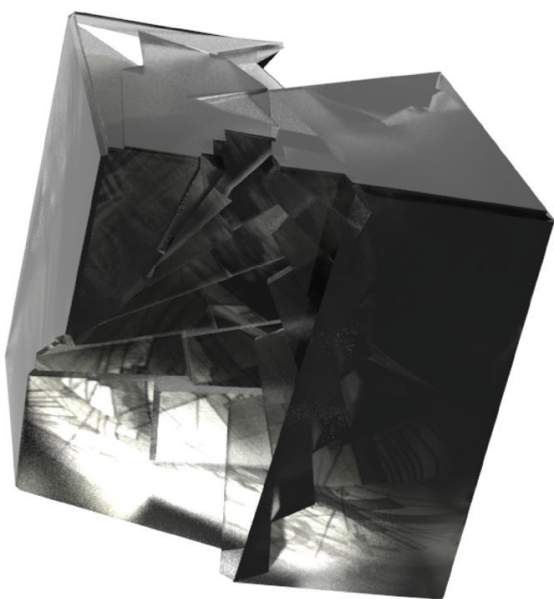


Fig. 5. Stage I.

Recognition. A Victorian Building (first reduction operated by the filtering process) is further filtered and abstracted according to the user experience and expectations.
Fig. 6. Stage 2.

Fragmentation, Clustering ....information begins coacting with others via aggregation, fragmentation and clashing. Bits of data are lost in the process, and what is left further adapts, forming a larger piece of information with other fragments'.
Stage I. Recognition

In Psychology, the process of recalling old memories is labelled as 'reconstruction', while the formulation of new memories is named 'construction'. As mentioned previously, the two processes tend to blend when a memory is retrieved, it is often subject to alteration. However, the 'falsification' of an event happens much earlier. The perception of reality is altered according to each individual's background and aspirations, mood and health condition. In this first stage called Recognition, the fundamental alteration of reality is caused by filtering and selecting information. The human brain stores information by optimizing it. We store data used to generate an image or word or scene from our past, which is why we do not remember every detail of a moment, but with a high probability, we will remember a significant aspect of it, thus adapting the other information to that and re-constructing the rest as a consequence of it. Each time we remember something, we are producing a fresh construction. The case study exemplifies this process: the prevalent style of the buildings surrounding the site is Victorian. A typical Victorian building is selected for the exercise (Recognition I). The information is filtered and reduced according to the subject background etc. (Recognition 2), (fig. 5).
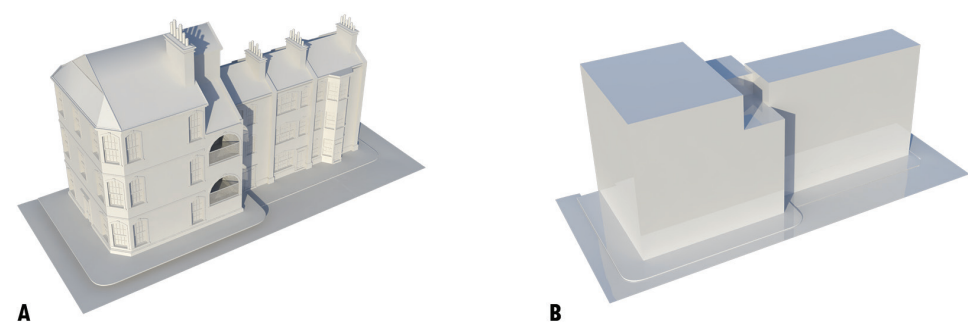

Stage 2. Fragmentation / Clustering

Once a certain reality recognition is filtered and stored, it becomes part of a constructed past, a memory. The human brain does not associate it directly with the living 'now' anymore, yet the filtering process evolves into the retentional mechanism and the single entity begins to deal with a larger set of stored information. This information begins co-acting with others via aggregation, fragmentation and clashing. Bits of data are lost in the process, and what is left further adapts, forming a larger piece of information with other fragments.

The case study exemplifies this process: Entire pieces of the surrounding portion of the city are collected in the form of abstract blocks (Recognition $112+$ Accumulation). The entities are clustered together undergoing projection, Boolean and intersection processes (clustering, fragmentation). The pieces of information collapse in a single yet multi-layered entity (fragmentation, merging), (fig. 6).
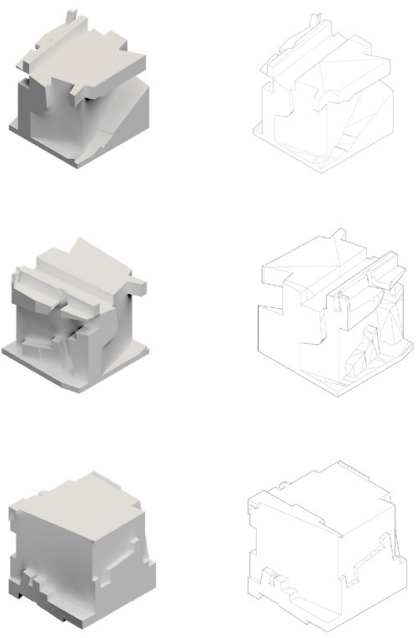
Fig. 7. Stage 3. Projection, Manipulation. The 'now' moment in design, highly affected by contingency and arbitrariness. The clustered information further reacts and moulds according to future projections and immediate contingences.

Fig. 8. The clustered object begins losing some components reacting to actual necessity: the volume breaks to accomfracte cossing infrastructure and slopes connecting diverse levels of the site.

Fig. 9. The process is mutual, the area surrounding the main intervention resonates its presence in the same way reality perceived in a specific situation is subject to alteration by the temporal object (observer).
Stage 3. Projection, Manipulation

The reason the entire process of storing and filtering information exists is to advance the human capability of foreseeing events. This relates to an inherent survival instinct. During the third phase of the process, altered clusters of information are further manipulated to best serve purposes and projected goals.

At this stage, further manipulations, either conscious or not, contribute to the ultimate (not quite literally as all the illustrated processes coexist and loop in a chaotic and nonlinear way) falsification of a temporal entity.

The single entity starts to compromise its nature by being manipulated to serve the purpose, a future goal and contingency of the current 'now'. e.g. from the case study: the cluster breaks in pieces for allowing an infrastructure to pierce through the volume (projection, manipulation). The volume is scattered to accommodate the program and splits to connect multiple levels (projection, manipulation). This phase is highly affected by arbitrariness and contingencies (figs. 7-10).
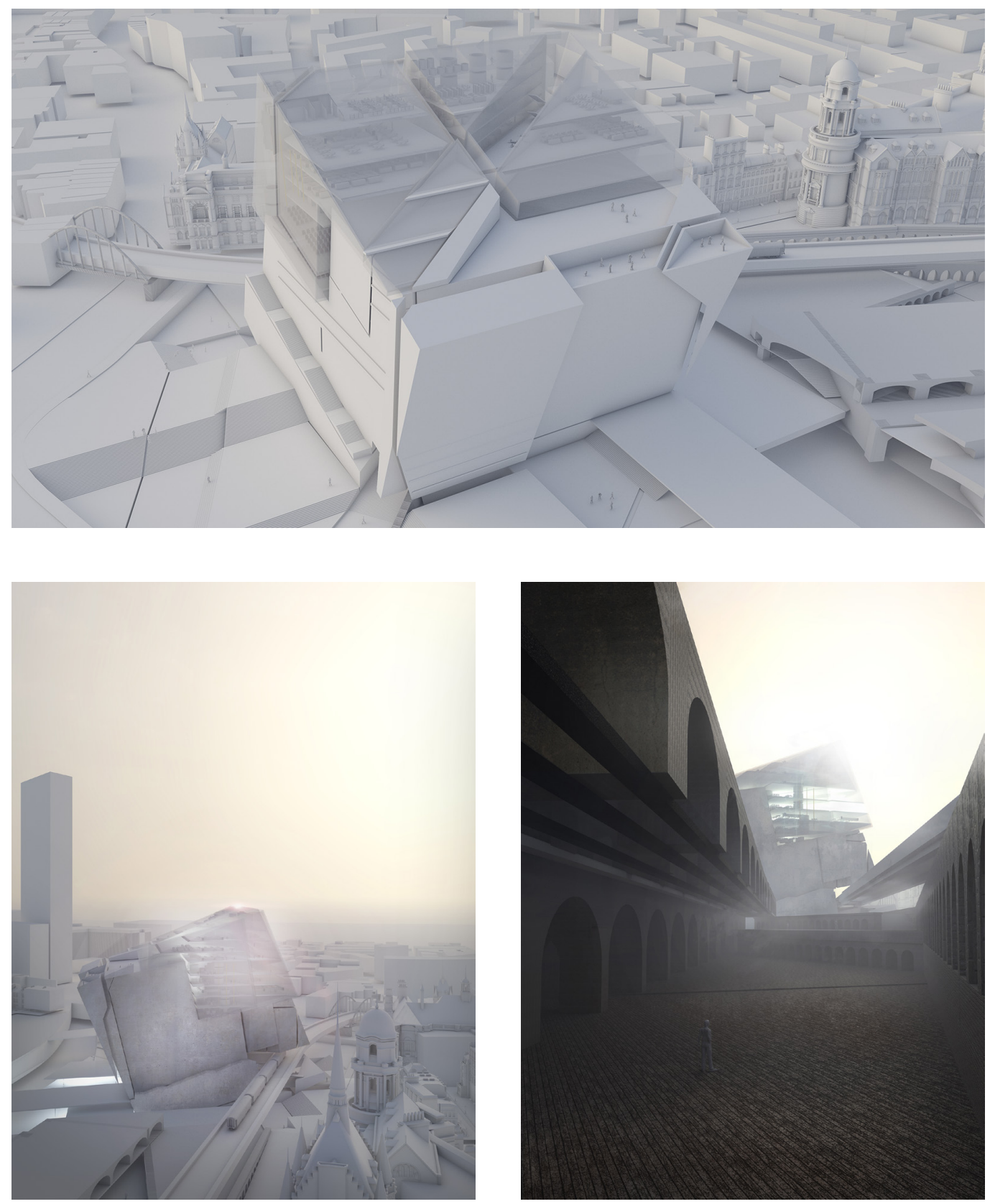
Fig. I0. Fragments of fragments. Programmatic and structural studies influenced by a retentional mechanism at the same time determining future manipulations.
Fig. I I.The structure can operate in a quasifractal mode. 'Sectioning' temporal systems it is possible to deepen the investigation and examin the sublayers of this

model. Some sublayers

have a direct reflection on the main series of now events (surface of perceived reality) (SLI) others remain semi-

muted below the now events line (SL2).

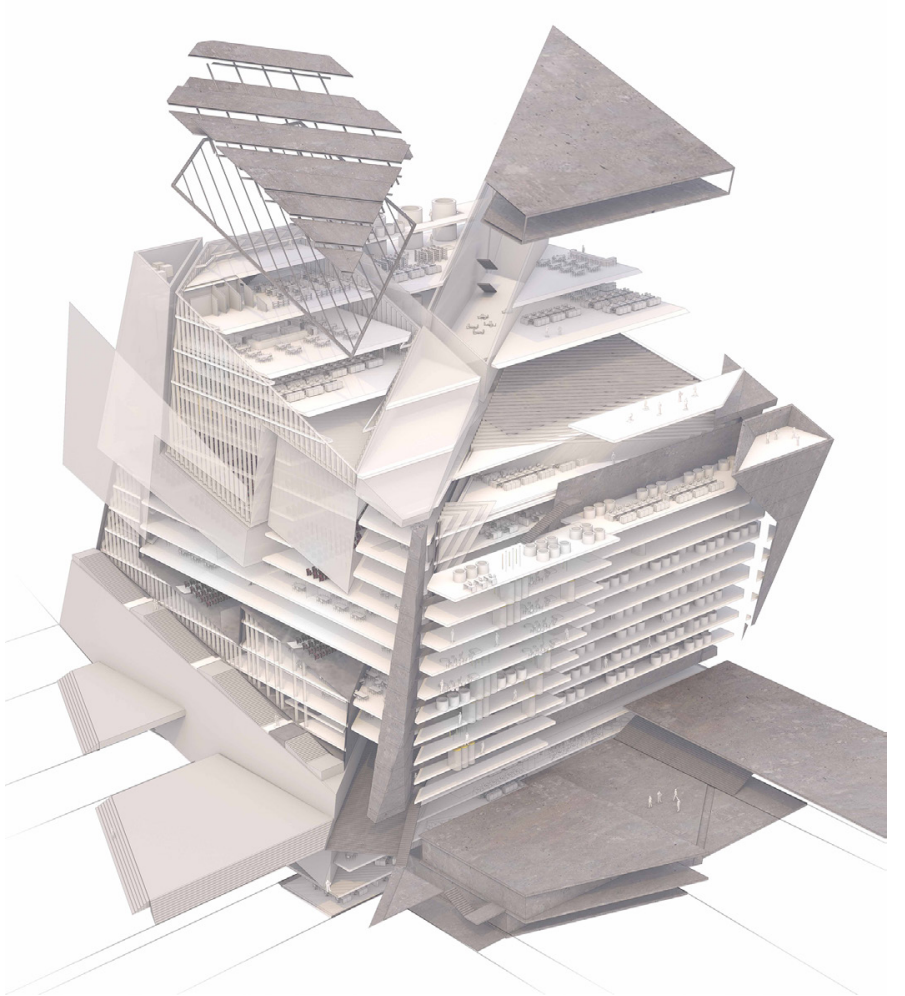

The process repeats itself, allowing for more complexity and iterations, creating spatialized temporal loops (figs. I I, I2).

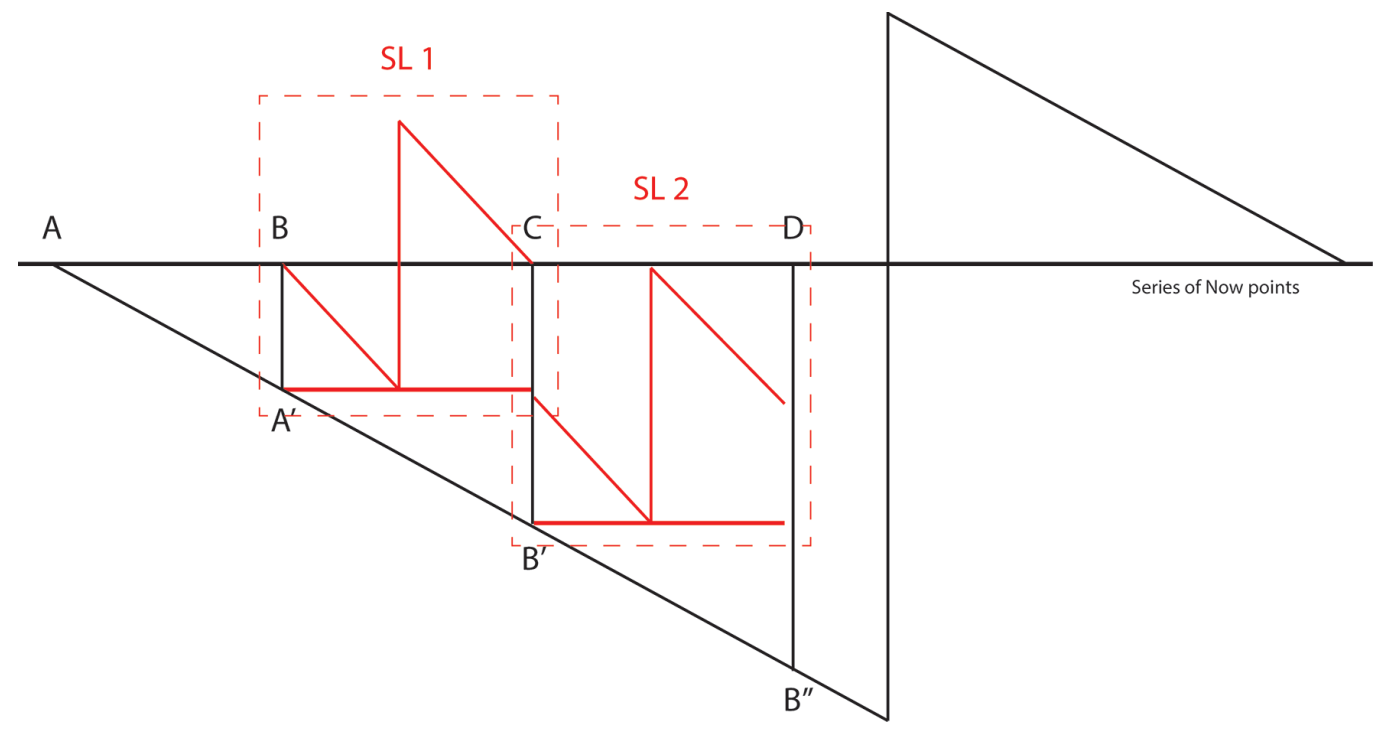


Fig. 12. An exemplification is the Vivi sectioning of the fragments

resulting from Stage 2 .

These sublayers are

These sublayers are

in their singularity in

in their singularity in a

second moment (SLI,

nonlinear approach) and

serve the purpose of

further projections. The

fragments accommodate

different programs and

split the department

according to wet and

dry areas as per labs

requirement $(S L I$ Stage 3 .

Projection, Manipulation)

Occasionally the different

departments can open up

departments can open up

to neighbour ones if any

undergoing multi-team
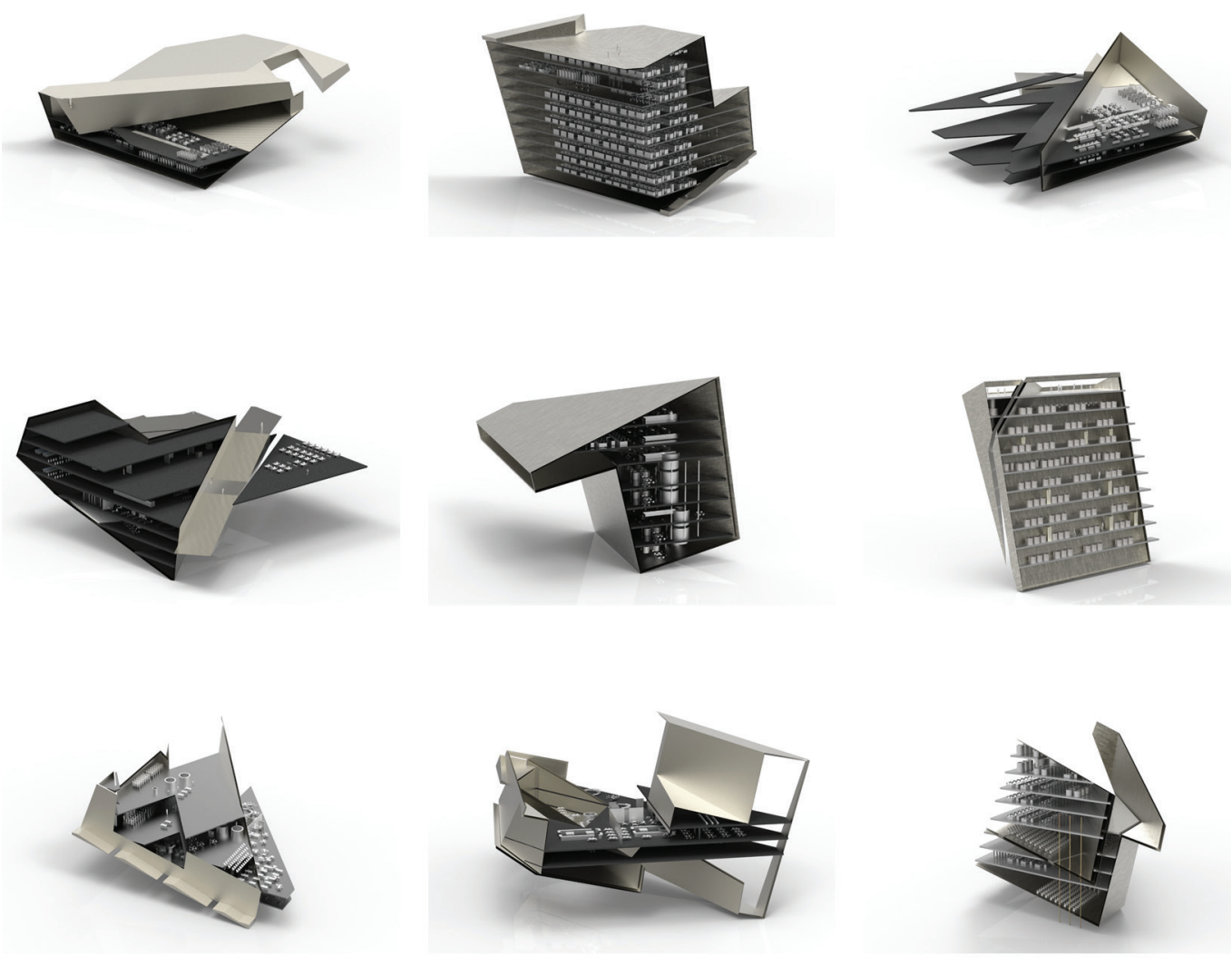

References

Newton Isaac (1934). Mathematical Principles of Narural Philosopy and His System of the World. (I st American ed., carefully rev. and corr. / with a life of the author, by N.W. Chittenden). University of California Press: Berkeley.

Rynasiewicz Robert (2014). Newton's Views on Space,Time, and Motion. In The Stanford Encyclopedia of Philosophy. (Summer 20 I 4 Edition), Edward N. Zalta. <https://plato.stanford.edu/archives / sum20 | 4 / voci / newton-STM />

Husserl Edmund (1973). The Phenomenology of Internal Time-Consciousness. Indiana University Press: Bloomington.

Kelly Michael R. (2020). Phenomenology and Time-Consciousness. In The Internet Encyclopedia of Philosophy.< https://www. iep.utm.edu/phe-time>.

Schacter Daniel L., Addis Donna Rose, Hassabis Demis et al. (2012). The future of memory: remembering, imagining, and the brain. In Neuron n.76, pp. 677-694.

Author

Nicolas Turchi, University of Bologna, turchinicolas@gmail.com

To cite this chapter: Retention and protention methodology: Edmund Husserl's phenomenology as a multidimensional design approach. In Arena A., Arena M., Brandolino R.G., Colistra D., Ginex G., Mediati D., Nucifora S., Raffa P. (a cura di). Connettere. Un disegno per annodare e tessere. Atti del $42^{\circ}$ Convegno Internazionale dei Docenti delle Discipline della Rappresentazione/Connecting. Drawing for weaving relationships. Proceedings of the 42th International Conference of Representation Disciplines Teachers. Milano: FrancoAngeli, pp. | 425 - 1433. 